\title{
CONVERSAS ENTRE PROFESSORES: PRODUÇÃO DE CURRÍCULOS NOS PROCESSOS DE FORMAÇÃO CONTÍNUA
}

Graça Reis ${ }^{1}$

Marina Santos Nunes de Campos²

\section{INTRODUÇÃO}

\begin{abstract}
Bem antes de fazer resplandecer, em sua escatológica glória, a grande luz (luce) do Paraíso, Dante quis reservar, no vigésimo sexto canto do Inferno, um destino discreto, embora significativo, à pequena luz (lucciola) dos pirilampos [...] O espaço todo é salpicado constelado, infestado - de pequenas chamas que parecem vaga-lumes, exatamente como aqueles que as pessoas do campo, nas belas noites de verão, veem esvoaçar, aqui e ali, ao acaso de seu esplendor, discreto, passante, tremeluzente. (DIDI-HUBERMAN, 2011, p.1112).
\end{abstract}

Em fevereiro de 1975, 35 anos após ter escrito uma belíssima carta sobre a aparição dos vagalumes e nove meses antes de ser brutalmente assassinado, Pasolini teorizou sobre o desaparecimento dos vaga-lumes que teriam sido engolidos pela forte luz dos holofotes do fascismo triunfante, tese histórica dialogada com o momento político italiano da época.

Sobre esta tese, Didi-Huberman (2011) pondera que ao assumir o desaparecimento dos vagalumes, estamos vendo somente a noite escura ou a ofuscante luz dos projetores, agindo como os vencidos: "é estarmos convencidos de que a máquina cumpre seu trabalho sem resto nem resistência. É não ver mais nada" (p.42). Ele nos indica a importância de evidenciar as mazelas de uma máquina autoritária sem lhe atribuir rapidamente uma vitória definitiva e conceder a ela o crédito do que nos pretende fazer.

Nesse sentido, o autor revoga previsões apocalípticas nos levando a compreender que se as luzes dos vaga-lumes são intermitentes, passageiras, frágeis, não são os vaga-lumes que desaparecem,

\footnotetext{
${ }^{1}$ Doutora e Mestre em Educação pelo ProPED/UERJ. Graduada em Pedagogia pela Universidade do Estado do Rio de Janeiro - UERJ. É professora do Colégio de Aplicação (CAp) e do Programa de Pós Graduação em Educação (PPGE) da Universidade Federal do Rio de Janeiro.

${ }^{2}$ Doutoranda no Programa de Pós Graduação em Educação Da Uerj e professora do Colégio de Aplicação da UFRJ. É co-coordenadora do projeto de pesquisa e extensão "Conversas entre professorXs: alteridades e singularidades"no CAp/UFRJ e coordenadora do Curso de Extensão Conversas sobre práticas das Séries Iniciais do Ensino Fundamental, que ocorre no CAp/UFRJ.
} 
eles apenas se vão, estando invisibilizados apenas aos olhos do expectador que ficou parado no mesmo lugar onde já não é mais um lugar adequado para vê-los e desistiu de segui-los. Para vê-los, ainda que por pouco tempo, é preciso ser otimista e observá-los dançando na escuridão, marginais, sobreviventes, menores.

Esquivando-nos de "ver somente a noite escura ou a ofuscante luz dos projetores e buscando perceber em cada pequeno vaga-lume uma resistência", nosso objetivo neste texto é dar a conhecer o trabalho que vimos construindo na formação de professores com outras epistemologias e metodologias que tecem possibilidades de discutirmos a produção de currículos nas escolas, saindo do lugar dos holofotes das pesquisas que narram sobre o que se pensa sobre os currículos e não o que eles são no cotidiano.

O projeto se desenvolve como pesquisa e extensão acadêmica sobre a Formação Continuada de professores do ensino fundamental inicial da rede pública de ensino e da produção curricular cotidiana desses professores, compreendendo que por meio de suas narrativas, elaboradas em situação de roda de conversa, professores contam e escutam sobre suas experiências curriculares, tecendo uma rede de formação e de textos curriculares autorais.

A ação de pesquisa e extensão desenvolve-se a partir de uma metodologia/política que envolve os cotidianos das salas de aula, onde bolsistas do projeto acompanham turmas das séries iniciais da rede pública, trabalhando colaborativamente com os professores regentes e em rodas de conversa, promovidas no contexto de um curso de extensão voltado para a formação continuada, de onde emergem narrativas de experiências e de histórias de vida. Partindo do princípio que a formação se dá continuamente, ou seja, é um processo que começa com o nascimento e se tece por toda a vida dos sujeitos, discutimos a importância das memórias de vida como dispositivo de autoformação, pensando como o processo de autoconhecimento torna-se importante nos percursos de formação e o compartilhamento de narrativas de experiências como elemento crucial para a formação contínua e para a contribuição da valorização docente como autores de sua prática.

Ainda, consideramos a ideia de que as políticas de educação se tecem a partir dos embates cotidianos, o que significa que todas as ações desenvolvidas pelos praticantes $^{3}$ das escolas são também fruto de decisões e convicções políticas e expressam valores e objetivos também políticos. Sendo assim, pretende-se apresentar as ações de formação contínua que vimos desenvolvendo no

\footnotetext{
${ }^{3}$ Certeau (1994), historiador francês, ao pesquisas como os franceses consumiam cultura, constatou que não havia um consumo passivo, mas sim usos que recriavam o que lhes era dado para consumo. Por isso, ao invés de consumidores passou a chamar os sujeitos comuns de praticantes.
} 
grupo de pesquisa e extensão como uma política contra-hegemônica, que desinvisibliza os cotidianos escolares mostrando que o que parece posto como política de Formação Continuada e de Currículo é um processo de embates que se tece coletivamente e cotidianamente.

\section{SUPERANDO PRÁTICAS DE COLONIZAÇÃO: PREMISSAS DE UMA PESQUISA}

Temos assistido a um processo de desvalorização das práticas cotidianas dos professores que passa não só pela imposição de cartilhas e manuais que buscam direcionar o seu trabalho numa clara tentativa de "ensinar" o que elas "não sabem fazer", como também por uma infinidade de relatórios, provas e avaliações por meio dos quais se avaliam alunos e professores. Com esta pesquisa, na contramão desse processo, buscamos valorizar os conhecimentos docentes por meio da troca de experiências em rodas de conversa, entendendo que este conhecimento narrado é potente para compreendermos que saberes circulam nos espaçostempos escolares para além do que as políticas hegemônicas de Formação Continuada percebem e valorizam.

Compartilhar histórias tem se mostrado uma forma de tecer redes de solidariedade, permitindo que soluções, mesmo que provisórias, sobre questões que atravessam os cotidianos dos professores, sejam pensadas coletivamente. Na perspectiva de Santos (2010), essa solidariedade como forma de conhecimento é reconhecida como conhecimento/emancipação, pois possibilita reconhecer o "outro como legítimo outro" (MATURANA, 1999), superando a ideia de colonialidade imposta pelo pressuposto de que professores devem ser apenas executores de projetos pré-estabelecidos por um outro que supostamente sabe mais do que ele.

Essas práticas de colonização de grupos não hegemônicos são regularmente conhecidas e repetem com frequência uma lógica de subalternização, desvalorização, invisibilização dos sujeitos, de suas histórias e suas ações. Tzvetan Todorov (2003) traz uma contribuição inestimável à discussão deste processo de colonização com a publicação de 'A conquista da América'. A partir da análise da conquista do continente, especialmente buscando através dos documentos históricos existentes resquícios, indícios, das relações travadas entre colonizadores e colonizados, fomenta importante reflexão sobre a questão. Sobre Cristóvão Colombo ele relata:

Sua atitude em relação a esta outra cultura é, na melhor das hipóteses, a de um colecionador de curiosidades, e nunca vem acompanhada de uma tentativa de compreender: observando, pela primeira vez, construções em alvenaria (durante a quarta viagem, na costa de Honduras), contenta-se em ordenar que se quebre delas um pedaço, para guardar como lembrança. (TODOROV, 2003, p. 49) 
Pacheco (2008) nos ajuda nesta discussão sobre a colonização do trabalho docente e a necessidade de superarmos esse processo, ao apontar o que ele denomina dupla discriminação. A primeira discriminação se refere à crença de que a esses professores cabe apenas a função de reproduzir as propostas oficiais formuladas nas diferentes instâncias do poder, portanto, não há para essas praticantes um lugar na história. A segunda discriminação se relaciona aos saberes tecidos na prática que ocupam, nos discursos das pesquisas hegemônicas, um lugar de menor importância em relação à teoria, reforçando a dicotomia/hierarquia teoria-prática, conhecimento-senso comum ou saber-fazer, consagrada pelo pensamento moderno.

Buscando sair desse lugar, rompemos com os métodos convencionais de investigação, buscando uma superação do que a modernidade privilegiou: o conhecimento-regulação (SANTOS, 2009), que tem engessado a vida de todo dia e as práticas cotidianas em modelos empobrecidos, colonizadores e generalizantes, desconsiderando os sujeitos. Queremos assim, deixar de apenas confirmar “[...] aquilo que nossas hipóteses iniciais previam que encontraríamos” (OLIVEIRA, 2008, p. 142). Propomos aqui privilegiar o conhecimento-emancipação, que compreende o processo de conhecimento como "[...] uma trajetória entre um ponto de ignorância chamado colonialismo a um ponto de conhecimento chamado solidariedade" (SANTOS, 2009, p. 28).

Num contexto em que o entendimento hegemônico acerca da formação docente e da produção de políticas de currículo se encaminha crescentemente para a priorização do predomínio da técnica e da instrumentalização dos professores em detrimento de uma formação socialmente referenciada, buscamos produzir outros conhecimentos acerca do campo de Formação e dos currículos por meio do encontro entre professores dos anos iniciais do Ensino Fundamental atuando com crianças, ampliando e intensificando a troca entre os saberes e fazeres dos professores que estão em sala de aula, potencializando práticas cidadãs, emancipatórias e benéficas à construção da justiça social e cognitiva por meio da ampliação das trocas propiciadas pelo diálogo entre as narrativas.

\section{A PARTILHA DE EXPERIÊNCIAS COMO PERCURSO: A TESSITURA DE UMA METODOLOGIA}

Nossa metodologia se baseia nas rodas de conversas entre professores e de seus relatos de experiências e de histórias de vida. Todo esse material é registrado por meio da filmagem dos encontros e discutido pelo grupo que faz parte da pesquisa. Como método, a partilha de experiências tem se mostrado fundamental para o trabalho desenvolvido, pois possibilita um sentimento de pertencimento aos professores. Participar de um grupo, poder partilhar com ele suas histórias de vida 
e suas práticas curriculares bem-sucedidas ou não, permite aos envolvidos tecer relações de parceria, de pertença. Narrar com o outro e para o outro pode dar a esses professores um passado elaborado a partir de suas próprias palavras e ao dar-lhes um passado, também os ajuda a criar um futuro. Além disso, a partilha de experiências traz para os professores, a partir da sistematização do que é produzido, evidências sobre conhecimentos que estão presentes em seu cotidiano, mas que não são explicitados. Isso reforça para eles o reconhecimento de autoria. Galvão (2005), em seus estudos, aponta que "o conhecimento da compreensão do que é o ensino pode ser feito a partir da reconstrução dos acontecimentos pelos professores, numa situação de partilha das suas histórias” (p. 330). No seu entendimento, "isto se baseia nas premissas de que ensinar é experienciado como acontecimentos sociais complexos, que o conhecimento está organizado em teorias explicativas e, por sua vez, serve de lente interpretativa da compreensão da experiência de cada um" (p. 330). Desse modo, pesquisar por meio das partilhas de histórias e reflexões, tecendo diálogos narrativos pode nos ajudar a compreender que não há como dissociar prática e teoria, pois não há fazer sem pensar, o que evidencia a autoria dos professores no seu fazer pedagógico.

O procedimento metodológico do trabalho com as narrativas das professoras é usado na busca por compreensão dos cotidianos dos professores, suas aprendizagens, suas culturas e seus conhecimentos. As narrativas como método de investigação contribuem para uma aproximação entre sujeitos pesquisados e sujeitos pesquisadores, permitindo maior percepção sobre os significados que os professores dão às suas experiências, à avaliação que fazem dos seus processos de aprender e ensinar, assim como permitem um mergulho nos contextos vividos. A narrativa se constitui também como experiência formativa. Nesse exercício cotidiano, professores têm a possibilidade de (re)viver suas experiências e as dos outros que também narram. Assim, produzem diálogos entre o que fazem, o que desejam, o que lhes é possível fazer e o que pensam e nesse percurso se formam ou (auto)formam exercitando uma reflexão que vai além da naturalização das ações cotidianas, criando outros sentidos para a sua docência. Dessa forma, percebemos a formação como uma rede que se emaranha na produção de conhecimentos comuns (comuns porque estão ali no cotidiano e também comuns porque se tornam parte da vida de todos) e que também se singularizam por meio da riqueza que a vida de cada um nos mostra em suas particularidades e diferentes aprendizagens. Valorizamos assim a ideia da formação contínua, que também se constrói no diálogo, na relação com o Outro e na reflexão com as/a partir das práticas cotidianas, como reitera Costa-Hübes...

...a formação que acompanha a vida profissional do professor deve ocorrer de forma contínua, marcada por estudos, reflexões, retomadas, planejamentos, enfim, ações que contribuam efetivamente com seu exercício docente, incidindo, portanto, sobre a realidade escolar onde atua. Para isso, é preciso maior investimento na formação continuada, envolvendo os 
professores em momentos de estudos que contribuam decisivamente com o seu fazer pedagógico. (COSTA-HÜBES, 2013, p. 504)

Percebemos este processo de partilha de experiências como um percurso, pois com Bakhtin (2006), entendemos ser esta uma dinâmica em que é possível favorecer o acesso de uns a estratégias e reflexões de outros colegas professores, e vice-versa; assim como possibilitar que o próprio sujeito se "enxergue" de outros ângulos, num exercício de nos ver de fora, a partir do excedente de visão, nossas próprias atuações, desvelando e construindo outras práticas possíveis, pois assim

O excedente de visão é o broto em que repousa a forma e de onde ela desabrocha como uma flor. Mas para que esse broto efetivamente desabroche na flor da forma concludente, urge que o excedente da minha visão complete o horizonte do outro indivíduo contempla- do sem perder a originalidade deste. Eu devo entrar em empatia com esse outro indivíduo, ver axiologicamente o mundo de dentro dele tal qual ele o vê, colocar-me no lugar dele e, depois de ter retornado ao meu lugar, completar o horizonte dele com o excedente de visão que desse meu lugar se descortina fora dele... (BAKHTIN, 2006, p. 23)

Diante do exposto, o grupo vem desenvolvendo, desde 2010, diversas frentes de trabalho que objetivam promover a interação entre professores em formação, tendo como metodologia as rodas de conversa, partindo do entendimento de que, por meio da troca de experiências, há uma formação mútua, horizontalizada e mais próxima do real. Tais frentes englobam parcerias com municípios (Queimados, Itatiaia e Rio de Janeiro) para formação continuada de professores das séries iniciais do ensino fundamental, atuação direta do grupo por meio da inserção de bolsistas em sala de aula e dois cursos de extensão, um destinado a professores das séries iniciais e licenciandos em Pedagogia e outro que tem como público-alvo estudantes do Ensino Médio de um Curso Normal de formação de professores.

A partir das memórias e experiências narradas que emergem dessas ações, temos produzido uma série de materiais bibliográficos - artigos, memoriais, livros com narrativas de experiência - e mais recentemente vimos investindo na produção de materiais audiovisuais - fotos, vídeos - que tem nos ajudado a fortalecer e reconhecer o lugar das narrativas docentes.

Nesses dez anos em que vimos pesquisando a formação docente mergulhamos (Alves, 2008) em diferentes cotidianos escolares da educação fundamental inicial buscando compreender sua riqueza e complexidade, tecendo um entendimento compartilhado e mais horizontalizado sobre os currículos produzidos e sobre a formação docente. Realizamos, para isso, encontros semanais de estudo utilizando sempre como viés político epistemológico metodológico os estudos sobre e com as narrativas docentes, pois compreendemos que ao ouvir e conhecer professores talvez tenhamos acesso a respostas, mesmo que provisórias, para muitas perguntas que temos nos feito nestes tempos. Por 
meio do compartilhamento de suas produções temos a oportunidade de mostrar que os saberes que atravessam a docência estão para além do que se pensa conhecer sobre eles.

A rememoração da história pessoal que temos usado nos ajuda a compreender que a formação se dá a todo o tempo e que por meio dela é possível (re)direcionar percursos e mudar trajetos, ou seja, a formação é contínua e singular. Singular porque cada aprendizagem só acontece se vinculada aos entrelaçamentos das redes que se tecem pela vida afora. Isso nos leva à compreensão de que as aprendizagens só são possíveis de dentro para fora, contextualizadas ao que já temos e que toda formação é (auto)formação e todo conhecimento é autoconhecimento.

Segundo Souza (2006), narrar sobre si remete o sujeito a uma dimensão de "autoescuta de si mesmo, como se estivesse contando para si próprio suas experiências e aprendizagens que construiu ao longo da vida, através do conhecimento de si” (p. 14). Essa dimensão em que o narrador se propõe a escutar a si mesmo, está presente também nas filmagens realizadas. Ao ter que elaborar para si e para outro o que viveu acaba por sistematizar suas experiências, os saberes que delas emergem e, com isso, origina novas aprendizagens e significados.

Temos compreendido que ao trabalhar com professores precisamos estar implicadas com o processo de formação de adultos. Para Josso (2010, p. 34) o adulto, por seu status antropológico e sociológico, necessita de propostas que valorizem os processos formativos (GARCIA, 2013) experienciados pelo sujeito ao longo de sua existência. Quem narra suas experiências, fala sobre si mesmo, produzindo experiências modificadas pela reflexão. Ao narrar, professores e professoras podem identificar sua produção curricular cotidiana, tendo a possibilidade de rever e reformular concepções (JOSSO, 2010), pois ao viver uma experiência em sala de aula, produzindo currículos e conhecimentos, é necessário que professores possam refletir sobre o vivido e o produzido. A partilha de experiências-praticadas numa roda de conversa pode contribuir para dar significado ao vivido no presente gerando reflexões e novas experiências ao grupo.

Os vídeos de formação, produzidos a partir dessas narrativas, emergem e se enraízam no curso da vida, como uma maneira de representarem as suas existências e de se contarem para si mesmos e para os outros, em estreita relação com a sua vivência cotidiana. Os modelos biográficos e, mais especificamente, os vídeos com as suas histórias revelam modos discursivos construídos pelos sujeitos em suas dimensões sócio-históricas e culturais em uma interface entre memória e discursos de si.

Conhecer quem são esses professores, suas expectativas diante da educação, seus processos formativos, o que sentem, como agem diante dos desafios do mundo dentro e fora da escola, entre 
outras questões, parece um interessante e pertinente objeto de estudo, isso porque cada história contada revela um saber-dizer exatamente ajustado a seu objeto (ALVES, 2007).

Participar de uma roda de conversa, se deixar ver em um filme que narra histórias de vida e práticas curriculares, pode proporcionar a estes professores que vivem esta experiência, a partir da sistematização do que é produzido em transcrições, textos, vídeos ou fotografias, evidências sobre conhecimentos que estão presentes em seu cotidiano, mas que não são explicitados

\section{REMEMORAR EXPERIÊNCIAS VIVIDAS - NARRATIVAS DA/NA ESCOLA}

Temos percebido em nossa trajetória de pesquisa que o uso das narrativas como recurso metodológico decorre, em parte, do mal-estar surgido dentre os pesquisadores em falar sobre a escola em vez de falar a partir ou com a escola e, também, pesquisar sobre os professores em vez de com os professores (LIMA; GERALDI, C; GERALDI, W, 2015, p. 18). No entanto, em geral, as narrativas docentes apresentadas são sempre seguidas de explicações dos autores dessas pesquisas. Reconhecemos a importância destes trabalhos, mas compreendemos que, na medida em que trazem a leitura do pesquisador sobre as narrativas docentes acabam por subalternizar as interpretações docentes as dos pesquisadores. Essas interdições de outros discursos podem provocar a subalternização dos sujeitos narradores, desperdiçando o que eles têm para nos contar e, consequentemente, limitando o horizonte de "outras práticas discursivas e de conhecimento, bem como outros modos de interação entre os diferentes discursos e conhecimentos" (GARCIA; OLIVEIRA, 2010, p.44).

Nos livros organizados pelo grupo suprimimos esta lógica, as narrativas das experiênciaspraticadas vivenciadas em salas de aulas são acompanhadas das reflexões das próprias professoras e dos próprios professores ou, por vezes, são apresentados simplesmente os relatos em si. Esse procedimento visa reiterar professoras e professores de educação básica como autores e produtores de saberes, fazendo com que outras e outros docentes percebam o potencial do seu fazer cotidiano.

Segundo a professora Simone Alencastre, professora-autora no primeiro livro produzido:

Acho a proposta muito interessante porque trazer as experiências de professores é muito mais do que somente relatar um fato ocorrido em sala de aula, é rememorar as experiências vividas e atribuir novos significados para elas. Quando me proponho a escrever estou repensando minha prática, vendo as situações vividas com certo distanciamento, apoiada na memória do vivido e sentido, isso ajuda na elaboração de novas possibilidades de ações. Como professora gostei de ver minhas experiências em um livro escrito por professores porque vi nessas leituras a reflexão de novas ideias e também tive um sentimento de pertencimento. Quando leio esses relatos, algumas vezes, vejo minhas próprias atividades descritas e que ao 
serem publicadas parecem ganhar outro status, como se assim aquele saber tão meu, fosse validado. É muito importante observar o que acontece na sala de aula sendo valorizado como um saber reconhecido pela ciência, legitimando os conhecimentos produzidos na sala de aula e pelo professor. A aula acontece no ineditismo, no imediato, e na urgência que a sala de aula traz e muitas vezes o relato de experiências de professores é o texto que consegue mostrar a riqueza e a produção de conhecimentos e saberes pedagógicos desses momentos.

A relevância desse tipo de publicação repousa na ideia de que, embora tecidos localmente esses saberes e experiências narrados nos livros não se encerram em si, "porque reconstitui[em] os projetos cognitivos locais, salientando a sua exemplaridade, e por essa via transforma-os em pensamento total ilustrado" (SANTOS, 1996). Também podemos compreendê-los como um conhecimento tradutor, pois os saberes desenvolvidos localmente podem ser utilizados em outros contextos, na medida em que, por esse viés, todo conhecimento local é total.

Ainda,

Uma história contada, ao ser extraída pelo ouvinte do contexto narrado, pode ser recontextualizada em outras situações ou experiências, produzindo novas compreensões entre os contadores e os ouvintes. É isso que confere a narrativa um caráter quase universal (BRUNER, 1998, apud LIMA; GERALDI, C; GERALDI, W, 2015, P. 25).

Vemos a recuperação da diversidade dos discursos, desperdiçados pela lógica hegemônica, como capaz de ampliar nossas possibilidades de conhecimentos e argumentações e, ainda, produzimos uma "interdiscursividade, ou seja, a constituição de uma relação ecológica, de autoridades partilhadas, entre diferentes discursos" (GARCIA, OLIVEIRA, 2010, P.49).

Sendo assim, apostamos que divulgar relatos docentes acerca de suas aulas e o que aprendem com elas contribui para sistematizar saberes oriundos da formação cotidiana e ampliar os repertórios de outras professoras e outros professores permitindo que por meio das releituras das experiênciaspraticadas narradas possam (re)organizar suas próprias vivências cotidianas.

A narrativa abaixo foi retirada do segundo livro "Narrativas da/na escola" (2019) que buscou sistematizar e divulgar as tantas narrativas da escola que emergiam desses espaços pelos quais o grupo circula. Ali estão reunidas algumas narrativas escritas de professoras e professores da escola básica pública que contam acerca de suas práticas cotidianas e o que aprendem com essas histórias.

Ao pensar sobre narrativas escolares, trago uma lembrança registrada em meu diário de campo do ano de 2002, ocasião em que trabalhava com uma turma do $3^{\circ}$ ano do Ciclo de Alfabetização ${ }^{4}$ da rede municipal de

\footnotetext{
${ }^{4}$ Os Ciclos de Formação surgiram no final dos anos 90 e foram implementados no Município do Rio de Janeiro entre os anos de 2000 a 2009. Tinham, como pressuposto, a continuidade do processo de aprendizagem não interrompendo-o com reprovações durante os 3 anos correspondentes ao Ciclo.
} 
educação do Rio de Janeiro. A história da pequena Juliana ${ }^{5}$, eternizada em minha memória com seus 8 anos, é ressignificada cada vez que não compreendo os "silêncios", cada vez que percebo que silencio, cada

vez que aprendoensino ao me abrir para o encontro. Juliana, numa narrativa que poderia ser de qualquer

outro entre diversos educandos, contribuiu na formação da professora/pessoa que sou hoje. Ela não me descobriu; ela me criou! Eu fui para ensinar, mas fui eu que aprendi. Trago o relato que "passa novamente pelo coração".

Muita conversa, muita preparação e, finalmente, em uma “caixa surpresa”, entrego às crianças um caderno que nos acompanhará durante o $3^{\circ}$ ano do ciclo de alfabetização. Iniciamos um registro (livre escolha) para a capa do caderno, e após um combinado de como manteremos o material organizado, uma a uma, as crianças guardam seus cadernos nas mochilas.

No dia seguinte, como combinado, pegam os cadernos, e Juliana me entrega o seu com apenas 5 folhas. Somente um olhar profundo acompanha a entrega, nenhuma palavra!

- O que aconteceu? - pergunto, espantada e curiosa.

Cabeça baixa, olhos ao chão e nenhuma resposta.

Falo sobre os cuidados necessários com o material. Comparo cadernos e finalmente entrego um novo a ela, com muitas advertências a respeito do cuidado. Vejo um sorriso largo e uma pequenina correndo com o caderno na sala.

Uma semana depois, o novo caderno retorna, Juliana me entrega com alguns registros de exercícios feitos em sala e muitas folhas rasgadas, outras arrancadas... a expressão do olhar me chama atenção, não conseguia decifrar.

- O que aconteceu? - apressei-me em perguntar.

Novamente o silêncio, os olhos ao chão.

Faço um pequeno discurso sobre o cuidado que precisamos ter com o material e decido entregar um novo caderno à Juliana, advertindo que seria a última vez e mais blábláblá sobre os cuidados com o caderno, o que foi ouvido com bastante atenção.

Mais alguns dias, e Juliana me apresenta o caderno, pela $3^{a}$ vez, sem folhas... apenas a capa. Mais perguntas, menos respostas. Olhar profundo! Dessa vez, a irritação toma conta de mim. Pensei no gasto que tinha com aqueles cadernos ${ }^{6}$, pensei nas respostas que não vinham, pensei nas péssimas condições de trabalho, pensei naquela criança pequenina na minha frente, pensei no descaso do governo, pensei na família que não comparecia a nenhum encontro, pensei no que podia estar acontecendo... O que a fazia me entregar um caderno sem folhas ou com folhas rasgadas?

Decidi não mais perguntar, nem discursar sobre cuidados. Peguei um quarto caderno, dessa vez maior, encapei, coloquei adesivos e destaquei o nome dela na capa. Separei um lugar no armário da sala e disse que não mais poderia levar para casa. Devia permanecer na escola!

\footnotetext{
${ }^{5}$ Nome fictício.

${ }^{6}$ Apesar de a prefeitura oferecer material escolar para iniciar o ano letivo, costumávamos gastar parte do nosso salário para repor o que faltava ao longo do ano.
}

Revista Teias v. $20 \bullet$ n. 59 • out/dez $2019 \bullet$ Outras epistemologias e metodologias nas investigações sobre currículo 185 
Um lindo sorriso apareceu em seu rosto, e o ano continuou... Outras histórias se misturaram a essa, e quando estava quase esquecendo o que acontecera, encontro a mãe de Juliana que, com um abraço, me agradece por não mais enviar o caderno para casa.

A curiosidade retorna, e antes que pudesse perguntar, a mãe relata que o pai pegava as folhas do caderno para "cheirar".

Dessa vez, quem silencia sou eu! A garganta arde com vontade de gritar pedidos de desculpas por não ter escutado o muito que Juliana me falava em seu silêncio (LONTRA, 2019).

\section{EXERCITANDO A AMPLIAÇÃO DO MUNDO}

Arroyo (2011) complexifica nosso entendimento acerca da profissão docente ao nos elucidar que nós, professores, somos resultados de tensas relações em que a educação e a profissão docente estão inseridas, visto que precisamos lidar com imagens sociais pesadas e ultrapassadas com que ainda somos vistos pela mídia e pelo conservadorismo gestor, o que traz o imperativo de lutarmos por reconhecimento nosso e de nossos alunos.

Sabemos que atuar nos cotidianos escolares brasileiros significa, por vezes, atuar junto a infâncias, adolescências e juventudes submetidas a condições precarizadas de vida, onde percursos escolares são entrelaçados por trajetórias humanas desumanizadas. Tal realidade desestabiliza as experiências escolares discentes e docentes, desestabilização esta que pode ocasionar tanto uma precarização do trabalho, tornando-o um mal-estar, quanto impulsionar uma reinvenção da docência na medida em que esta se sente imbuída, diante das circunstâncias, a proporcionar experiências mais dignas e humanas nesses contextos.

Há uma concepção presente na nossa sociedade que desconsidera que o professor tenha um conhecimento específico da sua profissão desconsiderando os saberes docentes, desvalorizando seus profissionais. Tal concepção advém, segundo Alves, das "vozes do centro do "sistema educativo" a que chamamos de "voz oficial" que afirmam reiteradamente que os professoras/es são mal formadas/os e nada sabem. Tais afirmativas são produzidas a partir de uma visão que foca no não saber, sem que de fato haja um investimento em pensar acerca do que realmente sabem/fazem os docentes ou como constituem seus saberes/fazeres nos diferentes contextos de formação e atuação. Sendo assim, "é preciso que saibamos o que as professoras sabem, antes de propormos qualquer outra formação acadêmica" (ALVES, 2010, p. 1196).

Ao produzirem currículo cotidianamente estudantes e docentes entrelaçam os conhecimentos advindos dos conteúdos escolares com outros conhecimentos tecidos cotidianamente e em outros 
espaçostempos, por meio de uma influência recíproca entre os diferentes conhecimentos, que produz novos conhecimentos, inclusive conhecimento curricular. Embora em geral tais conhecimentos não estejam presentes nos discursos educacionais, as escolas reais já são um cenário de criação cotidiana de uma pluralidade de conhecimentos e valores capazes de desestabilizarem a lógica vigente no mundo. "E o fazem apesar dos inúmeros mecanismos de imposição e controle presentes nas escolas"(OLIVEIRA, 2012, p. 98).

Sendo assim, os currículos produzidos englobam uma diversidade de experiências e saberes muito mais amplos do que o currículo oficial propõe, na medida em que são criados e usados pelos diversos sujeitos que tecem os cotidianos escolares, entrelaçando as normas com suas vidas e valores. Isso quer dizer que mediante um conteúdo que deve ser ensinado e voltando-se para o imperativo de planejar experiências que visam essa intencionalidade, o docente enreda tais conteúdos com seus conhecimentos e critérios precedentes, que englobam muito mais que apenas o conteúdo como, por exemplo, o embasamento a partir de aulas anteriores que deram mais ou menos certo, a preocupação em garantir o caráter lúdico, o conhecimento que tem sobre o grupo para qual leciona e etc. Posteriormente, quando a aula acontece, há outros diálogos e entrelaçamentos, visto que o momento planejado não chega em um terreno vazio, pois mesmo crianças pequenas possuem suas redes de conhecimentos e subjetividades que interagem com a proposta, o que implica em imprevisibilidade, complexidade e riqueza.

Santos (2010), ao pesquisar movimentos sociais fora dos grandes centros hegemônicos, constata que a experiência social do mundo é muito mais ampla e variada do que a tradição científica e filosófica ocidental é capaz de conhecer e considera importante que esta variada experiência social deixe de ser desperdiçada como vem sendo e que tal desperdício nos dá a falsa ideia de que não há alternativas/saídas. Ainda, aponta que a ciência social tal como a conhecemos pouco nos serve se desejamos evitar esse imenso desperdício de experiência, validando-as para, assim, vislumbrarmos alternativas.

Por seu modo de produzir e conceber conhecimento, a razão moderna só se dá conta de "uma versão abreviada do mundo" (SANTOS, 2010, p.100), produzindo a desconfortável sensação, sentida por todos, de que as transformações do mundo não são acompanhadas de sua melhor compreensão, fluindo no paradoxo de que o mundo, embora sofra inúmeras mudanças, nos traz um sentimento de estagnação. Tal sentimento também é percebido nas frases-clichê sobre a educação. Comumente escutamos que a escola de hoje é idêntica a escola de 200 anos atrás, no entanto, um olhar mais crítico e aguçado permite notar que houve mudanças significativas, mas que não são valorizadas ou conhecidas. 
Cabe ressaltar que ao desconsiderar outras formas de conhecimento, o pensamento moderno subalterniza práticas e sujeitos sociais portadores de outros modos de estar no mundo e de conhecêlo, gerando um empobrecimento do horizonte de possibilidades de conhecimento e, consequentemente, outras possibilidades de futuro. O novo paradigma emancipatório, proposto por Santos (1996), volta-se justamente para a revalorização dos saberes não hegemônicos, que são tornados invisíveis aos olhos do paradigma vigente.

As implicações dessas lógicas monoculturais podem servir de base para a compreensão de como a docência vem sendo hegemonicamente percebida. As experiências docentes, advindas de diferentes trajetórias e vivenciadas nos mais diversos contextos, pouco são tomadas como escopo que mereça ser conhecido e valorizado, desperdiçando-se, com isso, uma fonte abundante de experiências e alternativas pedagógicas. Tal desperdício nutre discursos que apontam no sentido de que a escolarização e a docência não teriam mais razão de existir, pois a escola e os professoras são incompetentes, despreparadas, obsoletas e etc.

Este trabalho de pesquisa pretende, ao contrário de produzir inexistências ou realimentá-las, compreender os modos pelos quais docentes tecem os saberes próprios da profissão para, a partir disso, enriquecer os horizontes de possibilidades de futuros para a docência ao mesmo tempo em que busca discutir alternativas de formação coerentes com a maneira como são tecidos os conhecimentos da docência. Como já apresentado, a pesquisa social realizada a partir da lógica hegemônica é insuficiente para pensar a composição desses saberes, visto que esses são produzidos em contextos diversos, singulares e, portanto, não credíveis e desimportantes para esta racionalidade.

Visando a revalorização e credibilização dos saberes da docência, em contraposição à lógica hegemônica, entendemos que se faz necessário operar uma "ampliação do mundo através da ampliação e diversificação do presente" (SANTOS, 2010, p. 101), espaço-tempo possibilitado nas narrativas dos professores que revelam-se como uma experiência capaz de expandir o presente, trazendo outros conhecimentos e experiências para o debate acerca da formação docente, enriquecendo os horizontes de possibilidades e contribuindo para a credibilização dos saberes próprios da docência que são tecidos cotidianamente.

Essa ampliação tem nos possibilitado avistar os vaga-lumes dançando na escuridão, marginais, sobreviventes, menores. 


\section{REFERÊNCIAS}

ALVES. N. Nós somos o que contamos: a narrativa de si como prática de formação. In: Salto para o futuro, Histórias de Vida e Formação de Professores: boletim n. 01 mar. 2007.

A compreensão de políticas nas pesquisas com os cotidianos: para além dos processos de regulação. In: Educ. Soc., Campinas, v. 31, n. 113, p. 1195-1212, out.-dez. 2010.

ARROYO, Miguel G. Currículo: território em disputa. Rio de Janeiro: Vozes, 2011.

BAKHTIN, Mikhail. Estética da criação verbal. São Paulo: Martins Fontes, 2006, 468p.

CERTEAU, M. de. A invenção do cotidiano: 1. artes de fazer. Petrópolis: Vozes, 1994.

COSTA-HÜBES, Terezinha da Conceição. Formação continuada para professores da educação básica nos anos iniciais: ações voltadas para municípios com baixo Ideb. In: Revista Brasileira de Estudos Pedagógicos. Brasília: vol. 94, n. 237, p. 501-523, maio/ago 2013.

DIDI-HUBERMAN, Georges. Sobrevivência dos vaga-lumes. Belo Horizonte: Ed. UFMG, 2011.

GALVÃO. C. Narrativas em educação. Ciência \& Educação, v. 11, n. 2, p. 327-345, 2005.

GARCIA, A; OLIVEIRA, I. B. O mundo como narrativa polissêmica: diferença, relações de poder e interdiscursividade nos estudos dos cotidianos. In: OLIVEIRA, I. B. de (org.). Práticas cotidianas e emancipação social: do invisível ao possível. Petrópolis. DP ET Alli. 2010. p. 37- .49.

GARCIA. A. Encontros e processos formativos: uma conversa sobre currículos e estágio na formação de professores. Cadernos de Pesquisa em Educação - PPGE/UFES Vitória, ES. a. 10, v. 19, n. 38, p. 35-52, jul./dez. 2013.

JOSSO, M-C. Caminhar para si. Porto Alegre: EDIPUCRS, 2010.

LIMA, M. E. C.; GERALDI, M. G.; GERALDI, J. W. O trabalho com narrativas na investigação em educação. Educação em Revista, Belo Horizonte, v.31, n.01, p. 17-44, jan./mar. 2015.

LONTRA, Viviane. In: REIS, G.; CAMPOS, M.; FLORES, R. B.; ALENCASTRE, S.; LONTRA, V. (org.) Narrativas: histórias da/na escola $21^{\text {a }}$ ed. - Ed. Nova Aliança - Rio de Janeiro, RJ: 2019.

MATURANA, H. Emoções e Linguagem na educação e na política. Belo Horizonte: Editora da UFMG, 1999.

OLIVEIRA, I. B. Contribuições de Boaventura de Sousa Santos para a reflexão curricular: princípios emancipatórios e currículos praticadospensados. In: Revista e-curriculum, São Paulo, v.8 n.2, ago. 2012. Disponível em: <http://revistas.pucsp.br/index.php/curriculum〉. Acesso em: 14 out. 2018.

OLIVEIRA, I. B.; SGARBI P. Estudos do cotidiano \& Educação. Belo Horizonte: Autêntica, 2008.

PACHECO, Dirceu Castilho. Arquivos pessoais de praticantesdocentes e as pesquisas nos/dos/com os cotidianos. 157 f. 2008. Tese (Doutorado em Educação). Programa de Pós Graduação em Educação, Faculdade de educação, daUuniver- sidade do Estado do Rio de Janeiro, Rio de Janeiro: 2008.

SANTOS, Boaventura de Souza. Um discurso sobre as ciências. Porto: Afrontamento, 1996.

Para além do Pensamento Abissal: das linhas globais a uma ecologia de saberes. In: SANTOS, Boaventura de Sousa, MENESES, Maria Paula (org.). Epistemologias do Sul. São Paulo, Cortez, 2010, p. 31-83.

Para uma pedagogia do conflito. In: FREITAS, Ana Lucia Souza de, MORAES, Salete Campos de. Contra o desperdício da experiência: a pedagogia do conflito revisitada. Porto Alegre: Redes Editora, 2009. p. 15-4

SOUZA, E. C. O conhecimento de si: estágio e narrativas de formação de professores. Rio de Janeiro: DP\&A, 2006.

TODOROV, Tzvetan. A conquista da América: A questão do outro. $3^{\text {a }}$ ed. São Paulo: Martins Fontes, 2003. 


\section{CONVERSAS ENTRE PROFESSORES: PRODUÇÃO DE CURRÍCULOS NOS PROCESSOS DE FORMAÇÃO CONTÍNUA}

RESUMO: Este artigo objetiva dar a conhecer o trabalho de um grupo de pesquisa e extensão voltado para a formação contínua de professores realizada por meio de outras epistemologias e metodologias que tecem possibilidades de diálogos com a produção de currículos nos cotidianos das escolas. Discute sobre o papel do compartilhamento das narrativas docentes para os percursos da formação e valorização dos conhecimentos próprios da docência. Por meio do entrelaçamento entre as narrativas docentes oriundas das ações de extensão e os referenciais teóricos conclui-se que as narrativas docentes englobam uma diversidade de experiências e saberes muito mais amplos do que as políticas hegemônicas de Formação Continuada percebem e valorizam.

Palavras chave: Formação docente; narrativas docentes; currículos produzidos

\section{TEACHER CONVERSATION: CURRICULUM PRODUCTION IN CONTINUOUS TRAINING PROCESSES}

ABSTRACT: This paper aims to value the work of a research group, which addressed teachers continuing education through the use of epistemologies and methodologies that enabled dialogue possibilities within the standard curriculum development of schools. The article explores the sharing role played on the lecturers' narratives for their qualification and knowledge appreciation. Through the use of activities and theoretical references, connections among teaching stories are made. Hence, the study concludes that teaching narratives comprise a vast set of experiences and knowledge, generally neglected by the hegemonic policies of continuing education.

Key words: Teacher Education, Teacher's Narratives, Curriculum Making

\section{CONVERSACIONES ENTRE MAESTROS: CURRICULOS PRODUCIDOS EN LOS PROCESOS DE FORMACIÓN CONTINUA}

RESUMEN: Este artículo tiene como objetivo dar a conocer el trabajo de un grupo de investigación y extensión enfocado en la formación continua de maestros a través de otras epistemologías y metodologías que tejen posibilidades de diálogos con la producción de currículos en la vida diaria de las escuelas. Discute el papel de compartir las narrativas docentes para los recorridos de formación y valorización de los conocimientos propios de la profesión docente. A través del entrelazamiento entre las narrativas de enseñanza que surgen de las acciones de extensión y las referencias teóricas, se concluye que las narrativas de enseñanza abarcan una diversidad de experiencias y conocimientos mucho más amplios que las políticas hegemónicas de Formación Continua perciben y valoran.

Palabras clave: formación docente; narrativas docentes; currículums producidos

Submetido em Agosto de 2019

Aprovado em Dezembro de 2019

Revista Teias v. 20 • n. 59 • out/dez 2019 • Outras epistemologias e metodologias nas investigações sobre currículo 190 